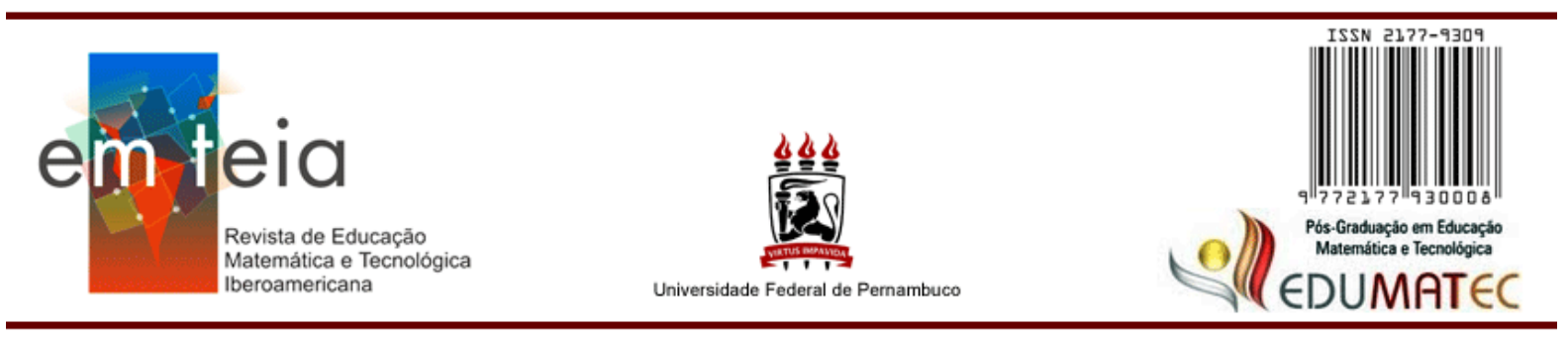

\title{
DE "VILÃO" A "MOCINHO":
}

a resolução de problemas como caminho alternativo para o incremento das crenças de autoeficácia de estudantes do sexto ano do Ensino Fundamental

Cristian Quintão Assis

cristianqassis@gmail.com

Edmilson Minoru Torisu

etorisu@gmail.com

Marger da Conceição Ventura Viana

margerv@terra.com.br

\section{Resumo}

O envolvimento, a dedicação e a persistência de uma pessoa após assumir uma tarefa e ao longo dela dependem de vários fatores. Dentre eles estão as crenças de autoeficácia, julgamentos que temos em relação às nossas capacidades para realizar algo. Quanto mais robustas as crenças de autoeficácia, maiores as chances de dedicação e persistência no enfrentamento de obstáculos. Na sala de aula de Matemática, a resolução de problemas pode servir como estratégia para incrementar as crenças de autoeficácia matemática de estudantes. Neste artigo, apresentamos resultados de uma pesquisa de mestrado, cujo principal objetivo foi desvelar contribuições que a resolução de problemas pode trazer para incrementar as crenças de autoeficácia matemática de estudantes do sexto ano do Ensino Fundamental, ao participarem de um projeto. Os instrumentos de coleta de dados foram entrevistas, questionários e registros de atividades dos estudantes. Os resultados mostraram que o projeto com resolução de problemas contribuiu para a melhoria das crenças de autoeficácia dos estudantes por meio da autorregulação da aprendizagem, além de ter criado um ambiente propício para que os estudantes pudessem se expressar com liberdade e adquirir, com isso, maior confiança em suas capacidades para resolver problemas.

Palavras-Chave: Resolução de problemas. Crenças de autoeficácia. Teoria Social Cognitiva. Psicologia da Educação Matemática. Autorregulação.

\footnotetext{
Abstract

Person's involvement, dedication and persistence after taking over and throughout a task depends on several factors. Among them are self-efficacy beliefs, judgments that we have in relation to our abilities to accomplish something. The more robust the self-efficacy beliefs, the greater the chances of dedication and persistence in facing obstacles. In the math classroom, problem solving can serve as a strategy to increase student's mathematical self-efficacy beliefs. In this article, we present the results of a master's research, whose main objective was to unveil contributions that problem solving can bring to increase the self-efficacy beliefs of students in the sixth year of elementary school, when participating in a project. The data collection instruments were interviews, questionnaires and records of student activities.
} 
The results showed that the problem solving project contributed to the improvement of students' selfefficacy beliefs through self-regulation of learning, in addition to creating an enabling environment for students to express themselves freely and acquire, with it, greater confidence in their ability to solve problems.

Key words: Problem solving. Self-efficacy beliefs. Social Cognitive Theory. Psychology of Mathematics Education. Self-regulation.

\section{Introdução}

Resolver problemas que envolvem Matemática faz parte da história do homem. De acordo com Ávila (2004), os primeiros problemas matemáticos parecem ter surgido no Egito por necessidades práticas. Há documentos daquela época, como o papiro de Rhind, que apresentam problemas matemáticos bastante interessantes. Além dos egípcios, os gregos, os chineses e outros povos também deixaram evidências de seu interesse pela resolução de problemas matemáticos.

No entanto, quando pensamos na resolução de problemas no contexto escolar, particularmente nas aulas de Matemática, esse pensamento é assombrado por sentimentos de angústia, impotência e incapacidade relatados por estudantes do mundo inteiro. Longe da euforia que surge como resultado de uma nova descoberta, a atividade de resolver problemas em sala de aula parece lançar os estudantes para dentro de um labirinto do qual eles não conseguem sair e, por isso, não querem entrar. A alternativa primeira é, então, solicitar que eles reproduzam algoritmos ensinados na lousa para responder a uma lista infindável de exercícios, não problemas. Mas, o que vem a ser um problema?

Dada a polissemia da palavra é importante que esclareçamos como tem sido compreendida, em Educação Matemática (EM), a resolução de problemas. Em conversas informais relacionadas à Matemática é comum que as pessoas utilizem a palavra problema como sinônima da palavra exercício. Dessa forma, uma frase como "vamos resolver um exercício" pode ser perfeitamente substituída por "vamos resolver um problema" sem que isso cause estranheza ou provoque reflexões acerca de uma possível diferença entre elas. Entretanto, quando estas palavras são discutidas em Educação Matemática há que se ter cuidado e diferenciá-las.

Kantowski (1981 apud ABRANTES, 1989, p. 3) considera que "um problema é uma situação que difere de um exercício pelo fato de o aluno não dispor de um procedimento ou algoritmo que conduzirá com certeza a uma solução". Dante (2002) corrobora a ideia acima ao afirmar que problema é a descrição de uma situação onde se procura algo desconhecido e não 
se tem previamente estabelecido nenhum algoritmo que garanta sua solução. E acrescenta que exercício serve para exercitar, para praticar um determinado algoritmo ou processo, portanto, diferente de problema.

Outra definição interessante para problema é dada por Onuchic e Allevato (2011, p. 80) para quem problema é um "ponto de partida para a construção de novos conceitos e novos conteúdos". Para Van de Walle (2001, apud ONUCHIC; ALLEVATO, 2011, p. 81), "um problema é definido como qualquer tarefa ou atividade para a qual não se tem métodos ou regras prescritas ou memorizadas, nem a percepção de que haja um método específico para chegar à solução correta", que se aproxima muito da definição de Kantowski (1981), anteriormente apresentada.

Há outras definições para problema no campo da EM. Dentre todas elas vamos utilizar a de Ávila (2004, p. 47) que considera que "problema é um desafio que põe à prova nossos saberes, nossa capacidade de interpretar, de detectar a informação relevante, de relacionar, operar, de antecipar, de organizar e de validar os procedimentos”.

Os ganhos ao utilizarmos a resolução de problemas em sala de aula pode trazer ganhos inestimáveis aos alunos, caso a concepção de problema do professor esteja em sintonia com definições como as apresentadas. A resolução de Problemas tem sido foco de pesquisas na área de Educação Matemática ao redor do mundo (ZUFFI; ONUCHIC, 2007). No Brasil, de acordo com essas autoras, a linha de pesquisa que explora a resolução de problemas ganhou fôlego e impulso quando da tradução, para o português, da obra de Krulik e Reys (1997), o livro do ano de 1980 do NCTM. Neste livro há um artigo de George Pólya (reproduzido do original de 1949) intitulado "How to solve it" que desencadeou uma onda de discussões em torno do assunto entre os pesquisadores brasileiros.

As discussões acaloradas em favor da resolução de problemas fizeram com que ideias relacionadas a elas respingassem na forma como tem sido concebido o ensino de Matemática no Brasil. Nota-se, por exemplo, que em documentos oficiais do Ministério da Educação e Cultura (MEC) há menções à resolução de problemas como promotora da aprendizagem matemática dos estudantes. Dentre esses documentos podemos citar os Parâmetros Curriculares Nacionais (BRASIL, 1998) que defendem que a resolução de problemas possibilita aos alunos mobilizarem conhecimentos e desenvolverem a capacidade para gerenciar as informações que estão a seu alcance. Em outras palavras, os alunos têm que parar, pensar e agir. Outro documento, este um pouco mais recente, é a Base Nacional Comum Curricular (BNCC), promulgada em dezembro de 2017 , de caráter normativo e que determina um conjunto 
progressivo de aprendizagens essenciais para crianças, jovens e adultos. Em vários momentos a BNCC faz referência à resolução de problemas. Um exemplo está na página 264, onde está escrito que

\begin{abstract}
Os processos matemáticos de resolução de problemas, de investigação, de desenvolvimento de projetos e da modelagem podem ser citados como formas privilegiadas da atividade matemática, motivo pelo qual são, ao mesmo tempo, objeto e estratégia para a aprendizagem ao longo de todo o Ensino Fundamental (BRASIL, 2017, p. 264).
\end{abstract}

Pelo exposto, a resolução de problemas parece ser mesmo importante para o desenvolvimento de habilidades matemáticas e consequente desenvolvimento cognitivo dos estudantes. Onuchic (1999) pontua que ao se ensinar Matemática por meio da resolução de problemas, os mesmos se tornam importantes não somente como um propósito para se aprender Matemática, mas, também, como um primeiro passo para se fazer isso. Para Pólya (1978), a resolução de problemas é fundamental, pois é através dela que o aluno vai aprender a se empenhar, às vezes arduamente, para chegar à solução.

\footnotetext{
Ensinar a resolver problemas é educar à vontade. Na resolução de problemas que, para ele, não são muito fáceis, o estudante aprende a despeito de insucessos, a apreciar pequenos progressos, a esperar pela ideia inicial e a concentrar todo o seu potencial quando ela aparecer. Se o estudante não tiver na escola a oportunidade de se familiarizar com as diversas emoções que surgem na luta pela solução, a sua educação matemática terá falhado no seu ponto mais vital (PÓLYA, 1978, p. 114).
}

Quando Pólya, nessa citação, trata de aprendizagem a despeito de insucessos e se refere às emoções que surgem na luta pela solução de um problema ou quando defende a necessidade de que o estudante aprecie cada pequeno progresso, ele nos conduz, ainda que não tenha sido essa sua intenção, a um olhar (muitas vezes desviado e ignorado) para o papel de fatores psicológicos para o sucesso (ou insucesso) da aprendizagem matemática.

Pudemos perceber, como parte do que foi discutido até agora, que a resolução de problemas pode contribuir para a aprendizagem matemática dos estudantes em vários aspectos. Contudo, os estudantes têm tido a oportunidade de vivenciar experiências agradáveis e de sucesso ao resolver problemas em aulas de Matemática? Os professores têm se preocupado em promover um ensino baseado na resolução de problemas que os munam de ferramentas que utilizarão em momentos posteriores e com confiança? Os estudantes confiam em si mesmos para resolver problemas? Adianta um discurso em favor da resolução de problemas como metodologia de ensino se o estudante não acredita ser capaz de resolver as situações que lhes são apresentadas? 
Todas essas perguntas, que não foram feitas para serem respondidas nesse texto, pretendem provocar uma inquietação/reflexão em torno de como os estudantes se percebem como aprendizes de Matemática. Se eles não acreditam que são capazes de obter sucesso diante de um problema, muito provavelmente não tentarão resolvê-lo ou, se tentarem, caso encontrem algum empecilho, desistirão. Eles não apreciarão, como escreveu Pólya (1978), pequenos sucessos.

Portanto, a discussão em torno das crenças do estudante sobre suas capacidades (no caso, capacidade para resolver problemas), que tem sido denominada na Teoria Social Cognitiva de crenças de autoeficácia, é central nesse artigo, recorte de uma dissertação de mestrado no campo da Educação Matemática.

As crenças de autoeficácia matemática desempenham papel importante na forma como o estudante se engaja em tarefas nesse domínio. Pessoas com crenças de autoeficácia robustas se empenham mais e são mais persistentes diante de um desafio. Por outro lado, crenças de autoeficácia pouco robustas levam as pessoas a desistir facilmente diante de dificuldades e causa apatia. Qual o professor de Matemática nunca se frustrou com alunos apáticos diante de suas propostas em sala de aula? Promover uma prática que tente, em alguma medida, incrementar as crenças de autoeficácia de estudantes pode ser tão importante quanto ensinar Matemática.

E onde entra, nessa discussão, a resolução de problemas? A ideia central partiu de nossa crença de que, a depender da forma como os problemas são propostos em sala de aula, os estudantes podem "viver" experiências que os façam acreditar que eles são capazes. Em outras palavras, o objetivo central do artigo é analisar como a resolução de problemas pode contribuir para fortalecer as crenças de autoeficácia matemática de alunos do $6^{\circ}$ ano do ensino fundamental.

Sendo as crenças de autoeficácia um conceito importante nesse estudo, delas trataremos na seção seguinte.

\section{Crenças de Autoeficácia: construto central na Teoria Social Cognitiva}

Todos nós, em algum momento de nossas vidas, já nos sentimos inseguros para realizar algo. Essa insegurança pode estar relacionada ao autojulgamento em relação às nossas capacidades em um domínio específico. Esses “julgamentos das pessoas em suas capacidades para organizar cursos de ação necessários para alcançar certos tipos de desempenho (BANDURA, 1986, p. 391) são denominados, na Teoria Social Cognitiva, crenças de 
autoeficácia. As crenças de autoeficácia são, essencialmente, as percepções que as pessoas têm sobre suas capacidades e são a base para a motivação humana, o bem-estar e as realizações pessoais. A menos que as pessoas acreditem que suas ações podem produzir o resultado esperado, elas terão pouco incentivo para se envolver nas tarefas e perseverar diante das adversidades. As crenças de autoeficácia são um determinante crítico de como os indivíduos pensam e se comportam (BANDURA, 2008).

A Teoria Social Cognitiva, da qual as crenças de autoeficácia são um construto central, considera que todos os indivíduos possuem uma capacidade de agência, ou seja, uma capacidade de manobra, um grau de liberdade que pode mudar os rumos que suas vidas irão tomar. De acordo com Torisu (2010, p. 19) ser agente é

ser capaz de fazer as coisas acontecerem de modo intencional. O indivíduo pode
interferir no curso dos acontecimentos de acordo com o seu interesse. Ele é um
participante ativo dos rumos que sua vida irá tomar, uma vez que estabelece metas
que serão alcançadas através de trajetórias escolhidas por ele mesmo.

Isso significa que o indivíduo não é passivo aos acontecimentos do meio. Ele possui a capacidade de reagir a eles, de acordo com seus objetivos. Esses objetivos, que todos nós determinamos para nossas vidas, são a fonte de nossa agência pessoal. Em outras palavras, dependendo do quão importante é para mim atingir certo objetivo, este pode regular o gasto de energia e a persistência na execução de ações que me levem a atingi-lo. As pessoas agem de acordo com seus interesses. Sua capacidade de agência permite que elas façam manobras de vida que poderão levá-las ao êxito.

A agência humana possui quatro características, de acordo com Bandura (2008, p. 1): Intencionalidade: As pessoas agem de forma intencional, ou seja, planejam suas ações de modo que elas conduzam ao resultado esperado. 2) Antecipação: $O$ futuro não pode ser previsto e não deve servir como fator de motivação para determinado comportamento. Porém, a simples representação cognitiva desse futuro, no presente, que antecipa um resultado desejável, pode servir de fator motivacional para ações do hoje. 3) Autorreação: As pessoas são capazes de ser autorreguladoras dos cursos de ações adequadas que, para elas, não produzirão os resultados esperados. 4) Autorreflexão: Cada indivíduo é capaz de realizar autoavaliações sobre seus pensamentos e ações e o significado que têm, para ele, os objetivos almejados.

Isso mostra que os indivíduos (agentes) possuem um "sistema de crenças e capacidades autorreguladoras, o que possibilita ao agente organizar cursos de ação" (BANDURA, 2001, apud DOBARRO; BRITO, 2010, p. 204). 
O nosso comportamento, as coisas que acontecem conosco e no nosso entorno se influenciam mutuamente numa relação recíproca. Nas palavras de Pajares e Olaz (2008), a forma como as pessoas interpretam os resultados do seu próprio comportamento informa e altera os seus ambientes e os seus fatores pessoais que, por sua vez, informam e alteram seus comportamentos futuros. A essa relação recíproca entre comportamento, ambiente e fatores pessoais, damos o nome de Determinismo Recíproco ou Reciprocidade Triádica, que pode ser esquematizado como a seguir:

\section{Figura 01. Reciprocidade Triádica na Teoria Social Cognitiva}

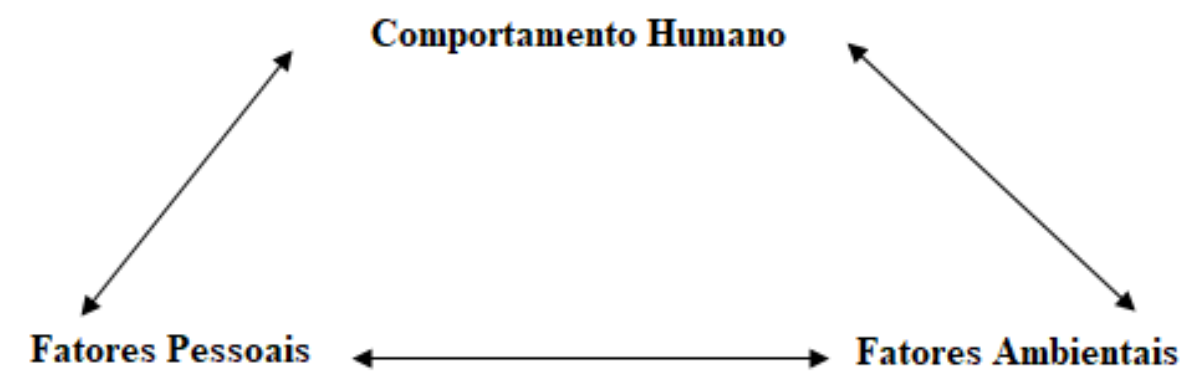

Fonte: Pajares e Olaz, 2008, p. 98

Essa figura mostra, como já discutido, a seguinte ideia: “o pensamento humano e a ação humana são considerados produtos de uma inter-relação dinâmica entre influências pessoais, comportamentais e ambientais" (PAJARES; OLAZ, 2008, p. 98).

Dos mecanismos da agência humana, a autoeficácia é central e também a sua base (BANDURA, 2008). A agência humana se relaciona às ações do indivíduo rumo a algo que ele deseja que aconteça. Contudo, ele somente irá agir caso acredite que suas ações podem produzir os efeitos que deseja, ou seja, se possuir crenças de autoeficácia robustas naquele domínio. Percebe-se, portanto, que essas crenças influenciam fortemente as escolhas que as pessoas fazem, ou seja, os cursos de ação que elas podem planejar, o esforço e a persistência dos indivíduos, principalmente diante de adversidades, e está ainda relacionada com a ansiedade pessoal diante de uma tarefa (DOBARRO; BRITO, 2010).

Vale ressaltar que, muitas vezes, a autoeficácia é confundida com outros construtos da Psicologia. Um deles é o autoconceito. A autoeficácia é mais específica, depende da tarefa, do objetivo, é relativamente maleável e orientada para acontecimentos futuros, enquanto o autoconceito está ligado a percepções mais gerais e estáveis estruturadas hierarquicamente e bastante normativas (PAJARES; OLAZ, 2008). Neves (2002) considera que a principal diferença entre esses dois constructos é em relação à sua especificidade, uma vez que o 
autoconceito é mais global e menos contextual do que as crenças de autoeficácia. Para ilustrar essa diferença, Bzuneck (2001, p. 117) nos apresenta um bom exemplo:

Um aluno pode revelar autoconceito positivo em relação a essa área de conhecimentos, mas, frente a um certo problema novo, poderá julgar-se sem condições de poder resolvê-lo, isto é, não terá crença de autoeficácia no grau desejado. Portanto, a crença de autoeficácia restringe-se, a cada caso, a uma tarefa bem específica com que a pessoa se defronta, enquanto que o autoconceito e as autopercepções de capacidade, mesmo quando se refiram a áreas específicas, ainda têm um caráter mais genérico do que autoeficácia.

Costa e Boruchovith (2006), baseadas em Pajares e Shunk (2001), reafirmam que indivíduos com autoeficácia robusta conseguem estabelecer um elevado nível de motivação que se traduz em maior esforço, persistência diante das dificuldades e obstáculos que são propósitos mais condizentes com o aprender e com o interesse em cumprir as metas.

Especificamente em relação à resolução de problemas matemáticos, mas ainda em sintonia com a discussão anterior, Pajares e Kranzler (1995) consideram que uma autoeficácia robusta faz com que os alunos tenham mais persistência e interesse em resolver problemas. Segundo esses autores,

Uma eficácia robusta pode servir bem aos alunos ao resolver problemas de matemática, não porque "faz com que" eles sejam melhores solucionadores de problemas, mas por que faz com que eles tenham um maior interesse e atenção em relação à resolução dos problemas, tendo maior esforço e maior perseverança diante de adversidades (PAJARES; KRANZLER, 1995, p. 3) ${ }^{1}$

Contudo, Pajares e Valiante (2006) destacam que de nada adiantará autoeficácia se habilidades e conhecimentos não estão presentes numa situação em que serão necessários, mas que a autoeficácia é determinante de como essas habilidades e conhecimentos serão requeridos.

Durante o percurso escolar, é muito importante que o estudante incremente suas crenças de autoeficácia porque, assim, acreditará mais em sua capacidade para resolver problemas e desafios a ele propostos e, como consequência, será mais persistente diante das dificuldades. Contudo, como surgem essas crenças?

\footnotetext{
${ }^{1}$ Tradução nossa. "A high sense of efficacy may serve students well when solving math problems, not because it "causes" them to be better problem solvers, but because it engenders greater interest in and attention to working the problems, increased effort, and greater perseverance in the face of adversity" (PAJARES; KRANZLER, 1995, p. 3).
} 
Segundo Bandura (1986), citado por Bzuneck (2004), quatro são as fontes que dão origem a essas crenças: as experiências de êxito, experiências vicárias, persuasão social e estados fisiológicos. Elas podem atuar de forma independente ou combinada.

Experiências de êxito: são experiências relacionadas com o êxito obtido em cada tarefa por cada indivíduo. Costa e Boruchovitch (2006, p. 98) defendem que essa é "a fonte mais efetiva e que possui maior influência sobre as crenças de autoeficácia, porque baseia-se nos resultados de experiências pessoais reais". Tomemos como exemplo um estudante resolvendo problemas envolvendo a multiplicação. "Se esse estudante obtiver sucesso na solução dos problemas com multiplicação, ele vai aumentar a sua crença de autoeficácia que permitirá a ele realizar atividades semelhantes no futuro" (MACHADO, 2014, p. 82). Mas, ao contrário, fracassos sucessivos podem reduzir as crenças de autoeficácia do indivíduo.

Experiências vicárias são as experiências que consistem em observar modelos sociais, ver pessoas com capacidades semelhantes obtendo êxito nas tarefas as quais se propõem a realizar. Por exemplo, se uma pessoa vê seu colega, que julga ter as mesmas capacidades, realizar uma tarefa com sucesso, ela se sentirá com mais confiança, acreditando em si mesma para realizar essa mesma tarefa.

Persuasão social estimula o indivíduo a se esforçar para obter sucesso. Ocorre por meio de frases incentivadoras de outras pessoas que possuem credibilidade na visão do indivíduo. Exemplos muito comuns de frases que podem incentivar uma pessoa, são: "Vamos lá! Você consegue!", “Parabéns! É isso aí!”.

Estados fisiológicos: o estado fisiológico da pessoa pode influenciar suas crenças de autoeficácia. Por exemplo, quando o indivíduo está prestes a ser avaliado, a ansiedade e o nervosismo podem atrapalhar essa avaliação, diminuindo as suas crenças de autoeficácia.

Incrementar as crenças de autoeficácia em certo domínio é importante, sobretudo no domínio da Matemática. Mas por quê? Torisu e Ferreira (2009, p. 169) consideram que "essa disciplina ocupa um espaço no imaginário coletivo que, muitas vezes, predispõe as pessoas a esperar pelo fracasso. As crenças dominantes destacam essa disciplina como "muito importante, essencial para a vida, mas muito difícil, destinada apenas para poucos”.

Essa citação mostra quão complicada é a relação que muitos estudantes estabelecem com a Matemática por considerarem que não são capazes de aprendê-la. Esse julgamento do estudante quanto à sua capacidade para aprender essa disciplina se deve, em boa medida, a baixas crenças de autoeficácia. Por isso reforçamos e defendemos que promover incrementos nas crenças de autoeficácia matemática dos estudantes pode ser saudável e resultar em melhores 
performances acadêmicas. Não estamos defendendo que crenças mais robustas irão, necessariamente, melhorar resultados de provas, por exemplo. Defendemos que estudantes com crenças mais robustas serão mais dedicados e persistentes diante das tarefas. Melhores resultados poderão ser consequência disso.

Por acreditarmos no potencial da resolução de problemas como algo que pode contribuir para a formação matemática do estudante, tanto cognitiva quanto no campo afetivo, o objetivo do estudo que deu base para esse artigo foi analisar como resolver problemas pode incrementar as crenças de autoeficácia de estudantes de sexto ano do Ensino Fundamental.

Partimos do pressuposto que, dependendo da forma como os problemas são apresentados, eles podem contribuir para a melhoria das crenças de autoeficácia dos estudantes desde que o professor consiga orquestrar o processo de forma a criar situações que se constituam em fontes de autoeficácia.

\section{Metodologia}

O estudo, de cunho qualitativo, contou com a participação de nove estudantes no momento inicial. Todos eram de uma turma do sexto ano de uma escola pública no interior de Minas Gerais. Dos nove, três foram tomados para análise.

Os estudantes que tiveram consentimento dos pais ${ }^{2}$ deveriam participar de encontros no contraturno. Nesse contexto, eles eram convidados a resolver problemas. No total foram 24 encontros distribuídos ao longo dos meses de março, abril e maio de 2018.

Para a coleta de dados foram utilizadas duas entrevistas. Uma inicial para sabermos como os estudantes se relacionavam com a Matemática e como se viam como aprendizes dessa disciplina. Outra final, na qual algumas perguntas retornaram e cujo objetivo foi coletar dados que pudessem evidenciar melhorias nas crenças de autoeficácia para resolver problemas matemáticos. Um teste diagnóstico também foi aplicado no início dos encontros para avaliarmos os conhecimentos matemáticos dos estudantes para, a partir daí, elaborarmos os problemas. Um instrumento muito importante nesse estudo foram as tirinhas (TORISU, 2010), um pequeno conjunto de perguntas escritas e entregues aos estudantes ao final de cada encontro

\footnotetext{
${ }^{2}$ Todos os procedimentos éticos para a participação dos estudantes foram realizados. O projeto da pesquisa foi aprovado pelo Comitê da Ética da universidade à qual se vincula o programa de pós-graduação no âmbito do qual a dissertação foi desenvolvida. O Certificado de Apresentação para Apreciação Ética (CAAE) número 79734717.7.0000.5150 foi aprovado e o parecer de aprovação teve número 2.445.243.
} 
para coletar suas impressões dos mesmos que pudessem, de alguma forma, trazer à tona mudanças em suas crenças.

Para a elaboração dos problemas levamos em consideração o que os nossos referenciais teóricos sinalizam. Em quase todos os encontros sugerimos problemas de tipos variados: sem solução, com excesso de dados, com mais de uma solução e problemas de lógica (DELAZERI; SILVA, 2013). Além disso, cuidamos para que a cada encontro fosse proposto um conjunto de mais ou menos quatro problemas com níveis diferentes de dificuldade de modo a permitir que todos pudessem acertar pelo menos parte deles. De acordo com Bandura (1993, apud BZUNECK, 2001), desafios mais fáceis num primeiro momento podem levar o estudante ao acerto e encorajá-lo a tentar outro, num nível mais alto. As experiências graduais de sucesso (experiências de êxito) são as principais fontes de autoeficácia. Outra estratégia importante que foi levada em consideração para a elaboração dos problemas foi o uso de embelezamentos motivacionais, que contribuem para se conseguir melhor envolvimento dos alunos nas atividades de aprendizagem. Embora não exista uma taxonomia de embelezamentos motivacionais, Bergin (1999) cita alguns tipos: introdução de novidades, conflito cognitivo, interação com amigos, relação com comestíveis, jogos etc.

Após a resolução dos problemas, os estudantes eram convidados a apresentar, caso desejassem, suas soluções ao grupo. Esta forma de reconhecimento do esforço do estudante pelo grupo (sobretudo com palavras de incentivo do professor) é uma forma de persuasão verbal que pode contribuir para que o estudante tenha mais credibilidade em suas capacidades, ou seja, suas crenças de autoeficácia.

\section{Os dados e a análise}

Como já informado, escolhemos os dados de três estudantes para análise: JVNC, Dila e Mary, nomes fictícios escolhidos pelos próprios estudantes.

\section{JVNC}

JVNC tinha 10 anos, era dedicado aos estudos e aprendia com facilidade. Na entrevista inicial disse que gosta de Matemática e a considera uma disciplina de conteúdos mais fáceis que as outras. Ao longo de sua vida escolar sempre obteve bons resultados em avaliações dessa disciplina que é, em alguma medida, resultado de sua capacidade cognitiva. Contudo, somente a cognição não é suficiente para explicar bons resultados. As causas do sucesso ou insucesso escolar são um misto da "interação entre cognição, motivação e afeto, pois o uso efetivo dos 
recursos cognitivos está fortemente vinculado a aspectos motivacionais e afetivos" (SOUZA, 2006, p. 111).

De nada adiantaria a capacidade cognitiva se o estudante não acreditasse nela. Provavelmente os resultados das experiências de JVNC ao longo da vida escolar o fizeram acreditar que ele era capaz de obter sucesso em suas empreitadas e isso, de alguma forma, foi incrementando suas crenças de autoeficácia matemática. $\mathrm{O}$ caminho inverso também ocorre. Crenças de autoeficácia mais robustas tornam o estudante mais confiante em suas capacidades e que elas podem levá-lo ao sucesso. O processo parece funcionar por retroalimentação.

Outra consequência importante associada às crenças de autoeficácia é o pensamento antecipatório (BANDURA, 1997; BANDURA, 2008), por meio do qual a pessoa traz o futuro para o presente convertendo os elementos desse futuro em elementos motivadores, ou seja, elementos que levam a pessoa a agir de determinada maneira, regulando suas ações. No caso da Matemática, estudantes com crenças robustas estarão mais motivados por anteciparem bons resultados. O contrário pode acontecer com os estudantes que não acreditam em suas capacidades para resolver problemas matemáticos.

Outras respostas de JVNC evidenciam altas crenças de autoeficácia. Por exemplo, ao responder às seguintes perguntas: Quantos problemas você conseguiu fazer? No que você achou mais dificil, você insistiu até o final?, feitas ao final do novo e décimo encontros, ele respondeu, respectivamente: Todos, eu continuei fazendo até acertar e Todos, tentei fazer tudo até o fim. Vários estudos (PAJARES; OLAZ, 2008; BANDURA, 2008) consideram que estudantes que demonstram maior crença em suas capacidades são mais persistentes diante de dificuldades.

Contudo, se JVNC possui crenças robustas de autoeficácia matemática, porque, ao perguntarmos se ele se sentia nervoso antes de uma prova de Matemática, ele respondeu: "Mais ou menos, porque qualquer coisa você erra a conta".

De acordo com Bandura (1986), um fator que influencia as crenças de autoeficácia são os estados emocionais como estresse e ansiedade. JVNC se sentia 'mais ou menos' nervoso antes das provas. Uma parte da resposta de JVNC nos chama a atenção: “[...] porque qualquer coisa você erra a conta". Essa parte sugere uma forma de compreensão de acerto de um problema baseada somente no resultado final de um cálculo, sem levar em consideração o caminho lógico percorrido pelo estudante. Se em suas avaliações o professor leva em consideração somente o resultado final de um estudante, corre o risco de provocar em seus alunos um estado emocional desfavorável, que pode influenciar seu desempenho e, por consequência, suas crenças de autoeficácia. Durante as correções, considerar todo o 
desenvolvimento do problema e não somente sua resposta (certo ou errado) pode ser prática importante na manutenção ou incremento de crenças de autoeficácia mais robustas. Isso evitaria, por exemplo, que JVNC associasse sucesso apenas ao acerto do resultado final, o que poderia diminuir seu temor pelo erro e deixasse de associar 'erro de conta' a fracasso.

Contudo, as experiências de êxito de JVNV, mais potente fonte de autoeficácia, eram recorrentes na vida deste estudante. Possivelmente, ao obter bons resultados nas avaliações, JVNC refletia sobre seus próprios resultados. Por meio da autorreflexão, "as pessoas tiram sentido de suas experiências, exploram suas próprias cognições e crenças pessoais, autoavaliam-se e alteram o seu pensamento e seu comportamento (PAJARES; OLAZ, 2008, p. 101). Mesmo em situações de estresse, JVNC parecia perseverar. Mesmo não acertando todos os desafios propostos nos encontros "um fracasso eventual após uma série de sucessos terá pouco impacto sobre as crenças positivas de auto-eficácia" (BZUNECK, 2001, p. 122).

Outra resposta interessante de JVNC foi aquela dada à seguinte pergunta da entrevista final: Você se sente mais confiante para resolver os problemas de matemática propostos pelo professor? O estudante respondeu: "Sim. Acho que vou bem, mas não tenho certeza. Porque o professor ainda não passou nenhum problema parecido com esses pra gente".

JVNC ainda não tinha certeza se estava se saindo bem, embora seu histórico mostrasse o contrário. Os problemas que o professor propunha eram diferentes daqueles propostos nos encontros. Portanto, na compreensão do estudante, as atividades do ensino regular não serviam para balizar sua autoavaliação naquilo que se referia à confiança para resolver os problemas propostos nos encontros.

Os problemas de tipos diferentes propostos nos encontros obrigaram JVNC a encontrar mecanismos para resolvê-los, culminando na aquisição de novas aprendizagens. Caso os mecanismos utilizados para a resolução dos problemas sejam eficazes, eles podem ser utilizados posteriormente para solucionar problemas do mesmo tipo, gerando maior familiaridade e confiança para este tipo de tarefa. Isso corrobora as seguintes palavras de Brito e Souza (2015), baseadas em Pajares e Schunk (2001),

a aprendizagem envolve mudança e ocorre quando o indivíduo se defronta com uma tarefa desconhecida, através da qual ele vai aprender os procedimentos e componentes da tarefa. Isso implica em mudanças cognitivas, afetivas e comportamentais. Posteriormente, ao defrontar-se com a mesma tarefa ou tarefas similares conhecidas, ele colocará em ação os mecanismos desenvolvidos ao longo do tempo e em diferentes situações, escolhendo cursos de ação congruentes com as crenças que possui a respeito de sua capacidade e as exigências da tarefa. Ao se defrontar com uma tarefa, o indivíduo adquire familiaridade com as exigências e características da mesma e, conforme vai se familiarizando com a tarefa, também vai adquirindo maior confiança 
na realização de atividades similares, desenvolvendo confiança na própria capacidade de executar, com sucesso, uma determinada ação (BRITO; SOUZA, 2015, p. 30).

O exposto antes e durante a citação tem relação direta com o processo de autorregulação da aprendizagem. "A autorregulação é entendida na Teoria Social Cognitiva como um processo de governo do próprio comportamento, pensamentos e sentimentos voltados para obtenção de metas e guiados por padrões ferais de conduta" (AZZI; POLYDORO, 2010, p. 131). Mas como isso ocorreu no caso de JVNC?

É verdade que JVNC já possuía robustas crenças de autoeficácia, o que contribuía muito para que ele possuísse estratégias de autorregulação, como ler atentamente os enunciados, buscar estratégias para resolver os desafios e manter-se emocionalmente estável para ir adiante. Contudo, os novos tipos de problemas propostos nos encontros exigiram de JVNC novos esforços cognitivos e mais controle emocional para dar conta das novidades. Vejamos duas respostas desse estudante a duas perguntas da entrevista final:

\footnotetext{
Pesquisador: Você gostou de resolver os desafios propostos?

JVNC: Alguns.

Pesquisador: Por quê?

JVNC: Porque alguns tinha que pensar muito para resolver, por exemplo, aqueles que tinham umas contas muito grandes.

Pesquisador: Você se sente mais confiante para resolver os problemas de matemática propostos pelo professor?

JVNC: Sim. Acho que vou bem, mas não tenho certeza. Porque o professor ainda não passou nenhum problema parecido com esses pra gente.
}

Podemos reparar que os novos problemas exigiam "pensar muito para resolver" e eram diferentes daqueles dados na aula regular. Isso exigia de JVNC novas ações e controle emocional, ou seja, novas estratégias de autorregulação. Contudo, suas crenças de autoeficácia o faziam perseverar e, como resultado, na maioria das vezes, obter sucesso. Esses sucessos o faziam acreditar, por um processo autorreflexivo, que ele seguira o caminho correto. Em outras palavras, autoeficácia e autorregulação se influenciam mutuamente. Nesse sentido, Zimmerman e Cleary (2006), citados por Polydoro e Azzi (2008, p. 158) consideram que

A autoeficácia interfere na autorregulação porque está associada à antecipação,
seleção e preparação para a ação. Por sua vez e de modo recíproco, a autorregulação
influencia a crença de autoeficácia ao fornecer informações sobre o progresso, esforço
e tempo despendido na realização da atividade, participando de sua construção".

Sendo assim, podemos dizer que os novos tipos de problemas apresentados nos encontros contribuíram para que JVNC procurasse novas estratégias de autorregulação e, como consequência, aumentasse suas crenças de autoeficácia. 


\section{DILA}

Dila tinha 11 anos quando nos encontramos. Tinha muitas dificuldades em Matemática e não gostava da disciplina. Sempre se atrasava para os encontros. Em uma entrevista inicial disse não gostar de Matemática e justificou assim: "Por que é muito difícil". Essa ideia era sempre reforçada pela própria aluna ao longo do projeto. A despeito desse discurso, Dila participou durante todo o projeto.

Historicamente, Dila não apresentava bons rendimentos em Matemática e isso talvez pudesse ser a causa para ela não gostar da disciplina e, também, de possíveis baixas crenças de autoeficácia. As experiências de Dila em Matemática ao longo de seu percurso escolar não parecem ter contribuído para que ela acreditasse em sua capacidade para resolver problemas matemáticos. Isso está de acordo com Souza (2006, p. 119), quando considera que “[...] as crenças de autoeficácia matemática se formam ao longo dos anos escolares por meio das diversas experiências dos alunos com essa disciplina”. As experiências de Dila produziram, como resultado, baixas crenças de autoeficácia matemática. Bandura (1986) também se posiciona em relação à influência das experiências anteriores no surgimento das crenças de autoeficácia e considera que a maneira mais eficaz para uma pessoa se julgar capaz, ou não, de realizar uma atividade é avaliar seu desempenho anterior.

Dila não gostava de expor suas formas de solução dos problemas para os colegas. Essa insegurança e desconforto diante dessa situação parece indicar que Dila não acreditava no seu próprio potencial para resolver os problemas de forma correta. Isso parecia prejudicá-la, pois em alguns casos ela preferia apagar a sua solução, com a certeza de que estava errada e durante a correção constatava que isso não era verdade: "Tem vez que eu falo que eu não sei e eu acerto o problema e tem vez que eu apago o exercício antes de corrigir, só que aí eu vejo que alguns exercícios tavam certos”. Apagar as soluções antes mesmo de saber se estavam certas ou erradas é consequência de antecipação de resultados negativos. A antecipação, umas das capacidades humanas básicas de acordo com a Teoria Social Cognitiva, nos permite criar expectativas de resultados. Embora o futuro não tenha existência real, a representação cognitiva dele no presente antecipa resultados que nos fazem agir de uma maneira ou de outra (BANDURA, 2008). No caso de Dila, ao antecipar insucesso nos resultados, ela deixava à mostra a fragilidade de suas crenças de autoeficácia para resolver problemas e agia apagando suas soluções.

Dila ficava muito nervosa e até passava mal quando sabia que faria prova de matemática: "Fico muito nervosa, fico ansiosa, dá até dor de barriga". Todas essas reações podem indicar baixas crenças de autoeficácia. Sobre isso, Bzuneck (2001) afirma que estados fisiológicos 
podem indicar vulnerabilidade do indivíduo, indicando assim, julgamento de baixas capacidades em determinada situação.

As respostas da aluna à pergunta 'O que você achou dessas atividades?', que figurava nas tirinhas, foram as mesmas em praticamente todo o projeto: "achei dificil'. Dila considerou todos os problemas propostos difíceis. As capacidades cognitivas de Dila poderiam ser acionadas e levá-la ao sucesso. No entanto, pessoas com baixas crenças de autoeficácia têm pouco incentivo para agir em direção a determinado objetivo pois não acreditam em sua capacidade para atingi-lo. Nesse sentido, Pajares e Olaz (2008, p. 102) argumentam que "as ações das pessoas se baseiam mais no que elas acreditam do que no que é objetivamente verdadeiro". O desafio pode parecer mais difícil do que realmente é como resultado de baixas crenças de autoeficácia.

Dila apresentava dificuldades para resolver os problemas propostos, mas sempre tentava resolver alguns. Entretanto, suas dificuldades de interpretação dos enunciados ou a falta de persistência para compreendê-los e encontrar um caminho que a levasse ao sucesso faziam com que ela apresentasse soluções aleatórias como, por exemplo, utilizar todos os dados numéricos em operações fundamentais. Parecia ser uma estratégia para simplesmente cumprir o que havia sido solicitado pelo pesquisador. Um exemplo é a resolução do problema 1, da semana 9, em que a aluna soma todos os números presentes no enunciado do desafio.

Figura 29. Resolução do problema 1 da semana 9, pela aluna Dila

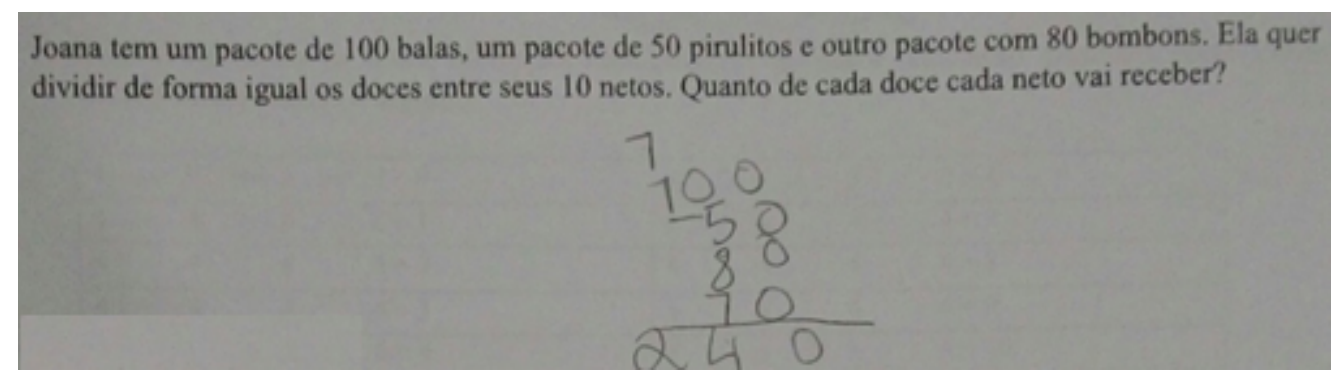

Fonte: Arquivo pessoal do autor.

Porém, isso não acontecia em todos os problemas. Um tipo especial parecia ser mais atraente para Dila: os problemas de lógica. $\mathrm{Na}$ entrevista inicial, Dila afirmou ter muita dificuldade em resolver problemas. Já na entrevista final, ao responder a mesma pergunta, a aluna disse achar problemas de matemática um pouco fáceis. Esses problemas fáceis, aos quais a aluna se referiu são os problemas de lógica. Isso ficou evidenciado quando, ao ser questionada na entrevista final se havia gostado de resolver os problemas propostos, a aluna afirmou ter 
gostado de resolver os problemas de lógica. Pode ser que Dila não tenha aumentando sua confiança geral para resolver problemas matemáticos, mas especificamente para resolver problemas de lógica. Isso pode ser explicado pelo fato de as crenças de autoeficácia serem "mensuradas em termos de julgamentos particularizados de capacidades [...]" (PAJARES; OLAZ, 2008, p. 108).

Observando cronologicamente as respostas dadas às tirinhas pela aluna ao longo dos encontros, uma resposta recorrente à pergunta "Sentiu-se confiante ao resolver o desafio?" foi "Mais ou menos". Porém, na semana 6, a resposta de Dila nos chamou a atenção por ser diferente das demais. Ela respondeu: "Eu acho que sim". Nesse dia, Dila resolveu todos os problemas. Isso pode significar que a aluna se sente mais confiante quando resolve todos os desafios, independentemente de ter acertado. Nas semanas anteriores, Dila sempre deixava pelo menos um problema sem resolver.

Ao que parece, Dila ainda possui crenças de autoeficácia pouco robustas no domínio dos problemas. Na entrevista final, ao ser questionada sobre sua confiança para resolver problemas de Matemática, ela disse que ainda não se sentia confiante. No entanto, ao se solicitar uma justificativa para isso, ela respondeu: "Porque tem aquelas atividades de raiz quadrada, eu não gosto não, aquelas expressões eu também não gosto. No início eu deixava sem fazer um ou dois exercícios, agora eu só deixo um”. Para justificar a sua falta de confiança para resolver problemas de Matemática ela não cita os problemas propostos nos encontros do contra turno, mas sim exercícios, provavelmente propostos na aula regular. Paradoxalmente, embora não se sentisse confiante, ela disse deixar de resolver apenas um, ao passo que antes deixava um ou dois.

Uma possibilidade de análise para isso é que os encontros, ao proporem problemas de tipos diferentes daqueles normalmente apresentados em sala de aula, possibilitaram à Dila uma experiência nova, na qual, ainda que de forma tímida, a fez melhorar um pouco suas crenças de autoeficácia. Isso não nos autoriza a dizer que os encontros aumentaram de forma substancial a segurança de Dila para resolver problemas matemáticos, mas podem ter mostrado que há outras possibilidades de apresentá-los, como nos problemas de lógica, dos quais ela mais gostava. Ao se empenhar para resolvê-los, há evidências de melhoria das crenças naquilo que se refere à persistência, ainda que ela não os acertasse. $\mathrm{O}$ aumento da persistência diante de obstáculos é um indicativo de melhoria de crenças de autoeficácia (BZUNECK, 2001; PAJARES; OLAZ, 2008). 
A capacidade autorregulatória de Dila para resolver problemas parecia frágil. Entretanto, quando o assunto eram os problemas de lógica, Dila parece ter encontrado estratégias de autorregulação que a faziam obter sucesso, ou mais sucesso do que em outros tipos de problema. Considerando novamente a relação recíproca entre autorregulação e autoeficácia, um incremento da primeira acarretará, como consequência, um incremento da segunda. Pode parecer pouco, mas no caso de Dila já foi um avanço.

\title{
MARY
}

Mary tinha 11 anos. Dedicada aos estudos, aprendia rápido o conteúdo. Disse gostar de Matemática e justificou: "Porque eu acho mais fácil do que as outras matérias" Ter facilidade em Matemática contribuía para o bom desempenho de Mary nos testes e, como consequência, permitia que ela vivenciasse experiências de sucesso, principal fonte de autoeficácia (BANDURA, 1986; PAJAREZ; OLAZ, 2008; NEVES, 2002).

Mary possuía crenças robustas de autoeficácia robustas. Vejamos algumas perguntas e respostas da estudante: Quantos problemas você conseguiu fazer? No que você achou mais dificil, você insistiu até o final? A aluna respondeu: "Todos, insisti até o fim" (Tirinha, 14/05/18). A persistência da aluna para resolver os problemas é apresentada na Teoria Social Cognitiva como uma característica de pessoas com crenças de autoeficácia robusta. Nessa direção, Pajares e Kranzler (1995, p. 3) consideram que

\begin{abstract}
uma eficácia robusta pode servir bem aos alunos ao resolver problemas de matemática, não porque "faz com que" eles sejam melhores solucionadores de problemas, mas por que faz com que eles tenham um maior interesse e atenção em relação à resolução dos problemas, tendo maior esforço e maior perseverança diante de adversidades. ${ }^{3}$
\end{abstract}

Mary parece ter considerado os encontros do projeto importantes para sua aprendizagem. Nas perguntas o que você achou dessa aula? ou o que você achou dessas atividades?, as respostas "estão sendo úteis" ou "estão me ajudando muito" foram recorrentes. Mary não explica de forma clara como eram as contribuições. Entendemos que a contribuição era em termos de aprendizagem de novos conteúdos e novas propostas de abordagem deles. Em alguma medida, a aprendizagem de novos conteúdos aumenta o repertório de possibilidades de

\footnotetext{
${ }^{3}$ Tradução nossa. "A high sense of efficacy may serve students well when solving math problems, not because it "causes" them to be better problem solvers, but because it engenders greater interest in and attention to working the problems, increased effort, and greater perseverance in the face of adversity" (PAJARES; KRANZLER, 1995, p. 3).
} 
estratégias para resolver problemas. Isso pode gerar, como resultado, aumento na confiança para esse tipo de atividade.

A resposta de Mary dada a uma pergunta da entrevista final mostra que ela passou a julgar os problemas mais fáceis do que eram no início do projeto.

Pesquisador: Como você se sente em relação ao início do projeto?

Mary: Os problemas agora estão mais fáceis que antes, porque antes eu tinha mais dificuldade do que agora.

Ao longo dos encontros, Mary foi se adaptando aos novos tipos problemas e encontrando estratégias para resolvê-los num processo cíclico de autorregulação. Esse processo é descrito por Zimmerman (2000 apud AZZI; POLYDORO, 2010, p. 139-140) da seguinte maneira:

o feedback de um desempenho anterior é usado para fazer ajustes em performances atuais, o que oferece possibilidade de um contínuo aprimoramento pró-ativo que inclui elevação de metas e desafios.

Aqui, mais uma vez, entendemos que a contribuição para o incremento dos processos autorregulatórios contribuiu para o incremento das crenças de autoeficácia de Mary, dada a relação de reciprocidade entre esses dois construtos.

\section{Considerações finais}

A Educação Matemática baseada na Resolução de Problemas é uma forte tendência atual. Resolver problemas pode levar o estudante a melhorar sua capacidade cognitiva. Contudo, isso será eficaz caso o estudante se envolva no processo de resolução ao interpretar, procurar estratégias para a resolução e chegar a uma resposta considerada satisfatória. Para que esse envolvimento ocorra é necessário que o estudante dedique tempo, seja persistente e isso só ocorrerá se possuir crenças de autoeficácia robustas. Portanto, o desenvolvimento e/ou incremento dessas autocrenças é fundamental para o sucesso do estudante em matemática.

Nessa direção e entendendo a importância da capacidade de resolução de problemas para o desenvolvimento do estudante e o papel das crenças de autoeficácia nesse processo, o objetivo de nosso estudo foi analisar como a resolução de problemas pode contribuir para fortalecer as crenças de autoeficácia matemática de alunos de uma turma do $6^{\circ}$ ano do Ensino Fundamental.

A partir das análises, pudemos identificar duas contribuições principais: 
1 - Variedade de tipos de problemas

Nesta categoria estão as contribuições que entendemos ser consequência da variedade de tipos de problemas propostos. Para JVNC e Mary, a variedade de problemas exigiu novas estratégias de resolução desenvolvendo a capacidade de autorregulação e, como consequência, as crenças de autoeficácia. Mas por quê? A autorregulação interfere nas crenças de autoeficácia pois os resultados desse processo fornecem informações sobre o progresso, esforço e tempo despendido, o que pode incrementá-las.

Naturalmente, não podemos generalizar os resultados e garantir que todos os estudantes que participarem de um projeto como o nosso terão sua capacidade autorregulatória aumentada e, por consequência, suas crenças de autoeficácia. As pessoas interpretam os resultados dessas ações de forma diferente e, além disso, as experiências anteriores são ingrediente importante para os julgamentos de capacidade. O que podemos afirmar é que uma variedade de tipos de problemas pode servir para que o estudante experimente maneiras diferentes de colocar em ação suas capacidades e, talvez, melhorar suas crenças.

2 - Ambiente contribuindo para criar fontes de autoeficácia

Nesta categoria estão as contribuições relacionadas ao ambiente criado nos encontros e o que ele proporcionou aos estudantes. Nos encontros tentamos criar um ambiente no qual eles se sentissem livres para expor suas ideias, pudessem apresentar suas soluções e entender que suas capacidades não estavam atreladas, necessariamente, ao acerto de todos os desafios. JVNC, Dila e Mary pareciam entender que "ser bom” em Matemática significa "não errar". Ao longo dos encontros puderam perceber que isso não é verdade. A maneira como foram propostos os problemas e conduzidas as atividades pelo pesquisador permitiram aos estudantes vivenciar experiências de êxito e vicárias, além de persuasões verbais, importantes fontes de autoeficácia. No caso específico de Dila, que apresentava dificuldades, foram apresentados problemas diferenciados para que ela pudesse cumprir e, dessa forma, ter experiências de êxito. Essa estratégia é mencionada na literatura sobre motivação (STIPEK, 1998; BZUNECK, 2010) com recorrência. Além disso, embelezamentos motivacionais (BZUNECK, 2010), que são estratégias para conseguir melhor envolvimento dos alunos, também foram utilizados. Alguns deles, de acordo com a classificação de Bergin (1999 apud BZUNECK, 2010), foram: introdução de novidades quando, por exemplo, foram propostos problemas diferentes daqueles usualmente utilizados na sala de aula regular daqueles estudantes, oficina de origami; relação com comestíveis; fantasia e humor. 
Esse estudo pode suscitar a realização de outros que aprofundem na compreensão da resolução de problemas matemáticos como alternativa para o incremento das crenças de autoeficácia dos estudantes nesse domínio.

\section{Referências}

ABRANTES, P. Um (bom) problema (não) é (só). Educação e Matemática. Faculdade de Ciências de Lisboa, v. 8, p. 7-10, 1989.

ÁVILA, M. G. de. História Da Matemática e Resolução De Problemas: uma Aliança Possível. 2004. 185f. Dissertação (Mestrado em Ensino de Ciências e Matemática), Universidade Luterana do Brasil, 2004.

AZZI, R. G.; POLYDORO, S. A. J. O papel da autoeficácia e autorregulação no processo motivacional. In: BORUCHOVITCH, E.; BZUNECK, J. A.; GUIMARÃES, S. E. R.

Motivação para aprender: aplicações no contexto educativo. Petrópolis, RJ: Vozes, 2010, p. $126-144$.

BANDURA, A. Social foundations of thought and action:a social cognitive theory. Englewood Cliffs, NJ: Prenice-Hall, 1986.

BANDURA, A. Self-Efficacy in Changing Societies. Cambridge: Cambridge UniversityPress, 1997.

BANDURA, A. A teoria social cognitiva na perspectiva da agência. In: BANDURA, A; AZZI, R. G.; POLYDORO, S. Teoria Social Cognitiva: conceitos básicos, Porto Alegre: Artmed, 2008, p. $69-96$.

BERGIN, D. A. Influences on classroom interest. Educacional Psychologist, London, v. 34, p. 87-98, 1999.

BRASIL. Parâmetros curriculares nacionais: matemática. Brasília, DF: MEC/SEF, 1998.

BRASIL. Base Nacional Comum Curricular. Brasília, DF: MEC/SEF, 2017.

BRITO, M. R. F.; SOUZA, L. F. N. I. Autoeficácia na Solução de Problemas Matemáticos e Variáveis Relacionada. Temas em Psicologia, Ribeirão Preto, v. 23, n. 1, p. 29-47, 2017.

BZUNECK, J. A. As Crenças de Auto-Eficácia e o seu Papel na Motivação do Aluno. In: BORUCHOVITCH, E.; BZUNECK, J. A. A Motivação do Aluno: contribuições da Psicologia Contemporânea. Petrópolis, RJ: Vozes, 2001, p. 116 - 133.

BZUNECK, J. A. Como motivar os alunos: sugestões práticas. In: BORUCHOVITCH, E; BZUNECK, J. A.; GUIMARÃES, S. E. R. Motivação para aprender: aplicações no contexto educativo. Petrópolis, RJ: Vozes, 2010, p. 13 - 42. 
COSTA, E. R.; BORUCHOVITCH, E. A auto-eficácia e a motivação para aprender Considerações para o desempenho escolar dos alunos. In: AZZI, R. G.; POLYDORO, S. A. J. (orgs.). Auto-Eficácia em Diferentes Contextos. São Paulo: Alínea, 2006, p. 87 - 109.

DANTE, L. R. Didática da resolução de problemas de Matemática. São Paulo: Ática, 2002.

DELAZERI, G. R.; SILVA, L. M. da. Vivenciando a Resolução de Problemas em Sala de Aula, VI Congresso Internacional de Ensino da Matemática, Anais, 2013. Disponível em: $<$ http://www.conferencias.ulbra.br/index.php/ciem/vi/paper/viewFile/649/41> Acesso em: 28 maio 2017.

DOBARRO, V. R.; BRITO, M. R. F. de. Atitude e Crença de autoeficácia: Relações com o Desempenho em Matemática. Educação Matemática Pesquisa, São Paulo, v. 12, n. 2, 2010.

KRULIK, R.; REYS (orgs.). A resolução de problemas na matemática escolar. São Paulo: Atual, 1997.

MACHADO, M. C. Gênero e desempenho em itens da prova de matemática do exame nacional do ensino médio (ENEM): relações com atitudes e crenças de autoeficácia matemática. 2014. Tese (Doutorado em Educação) - Unicamp, Campinas, 2014.

NEVES, L. F.2002. Um estudo sobre as relações entre a percepção e as expectativas dos professores e dos alunos e o desempenho na matemática. Dissertação de mestrado. Campinas: Universidade Estadual de Campinas.

ONUCHIC, L. de L. R. Ensino Aprendizagem de Matemática através da Resolução de Problemas. In: BICUDO, M. A. V. (org). Pesquisa em Educação Matemática. Concepções e Perspectivas. São Paulo: Editora UNESP, 1999.

ONUCHIC, L. de L. R.; ALLEVATO, N. S. G. Pesquisa em Resolução de Problemas: caminhos, avanços e novas perspectivas. Bolema - Mathematics Education Bulletin, v. 25, n. 41, p. 73-98, 2011. Disponível em: <http://hdl.handle.net/11449/72994>

PAJARES, F.; KRANZLER, JOHN. Role of Self-efficacy and General Mental Ability In Mathematical Problem-solving: A Path Analysis. University of Florida. Paper presented at the meeting of the American Educational Research Association, San Francisco, 1995.

PAJARES, F.; OLAZ, F. Teoria Social Cognitiva e auto-eficácia: uma visão geral. In: BANDURA, A.; AZZI, R. G.; POLYDORO, S. Teoria Social Cognitiva: conceitos básicos, Porto Alegre: Artmed, 2008, p. 97 - 114.

PAJARES, F.; VALIANTE, G. Self-efficacy beliefs and motivation in writing development. In: MACARTHUR, C. A; GRAHAM, S.; FITZGERALD, J. Handbook of writing research, New York/London: Guilford Press, 2006, p. 158-170. 
PÓLYA, G. A arte de resolver problemas. Trad. Heitor L. de Araújo. Rio de Janeiro: Interciência, 1978.

POLYDORO, S. A. J.; AZZI, R. G. Autorregulação: aspectos introdutórios. In: BANDURA, A; AZZI, R. G.; POLYDORO, S. Teoria Social Cognitiva: conceitos básicos. Porto Alegre: Artmed, 2008, p. 149 - 164.

SOUZA, L. N. I. Crenças de autoeficácia matemática. In: AZZI, R. G.; POLYDORO, S. A. J. (orgs). Autoeficácia em diferentes contextos. São Paulo: Alínea, 2006, p. 111 - 126.

STIPEK, D. J. Motivation to learn: from theory to practice. Englewood Cliffs, NJ: Prentice Hall, 1998.

TORISU, E. M. Crenças de autoeficácia e Motivação para Matemática: um estudo com alunos do Ensino Fundamental de uma escola pública de Ouro Branco (MG). 2010.

Dissertação (Mestrado Profissional em Educação Matemática). Ouro Preto: Universidade Federal de Ouro Preto (UFOP), 2010.

TORISU, E. M.; FERREIRA, A. C. A teoria social cognitiva e o ensino-aprendizagem da matemática: considerações sobre as crenças de autoeficácia. Ciências \& Cognição (UFRJ), v. v. 14, n. 03, p. 168-177, 2009.

ZUFFI, E. M.; ONUCHIC, L. R. O Ensino-Aprendizagem de Matemática através da Resolução de problemas e os Processos Cognitivos Superiores. Revista Iberoamericana de Educación Matemática, n. 11, p. 79-97, 2007. 